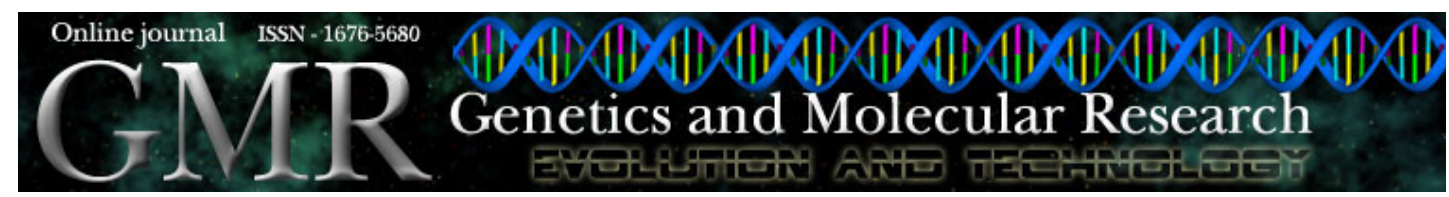

\title{
Estimates of heritability in a blanched asparagus population
}

\author{
Vanina Cravero, Enrique Cointry, Ileana Gatti and \\ Fernando López Anido \\ Cátedra de Genética, Facultad de Ciencias Agrarias, Universidad \\ Nacional de Rosario, CC 14 Zavalla (2123), Santa Fe, Argentina \\ Corresponding author: V. Cravero \\ E-mail: vcravero@fcagr.unr.edu.ar
}

Genet. Mol. Res. 1 (1): 90-95 (2002)

Received March 15, 2002

Published March 28, 2002

\begin{abstract}
To estimate the heritability values of characters frequently used as selective criteria, 32 half-sib families obtained from selected plants of three populations of the asparagus variety Argenteüil were evaluated in a randomized complete block design. The following characters were measured: days to emergence of the first spear, number and diameter of spears, number of stalks, plant height and average weight. The values of realized heritability were estimated and were compared with those obtained by the parent-offspring regression method. Phenotypic correlation coefficients between the different variables were significant. The values of realized heritability for most of the variables were moderate to high (between 0.18 and 0.68 ), except for days to emergence; lower values were obtained by the regression method. As there was a high degree of heritability, additive genetic factors contributed significantly to the genetic variance, which would allow the selection of phenotypically superior plants for asparagus improvement projects.
\end{abstract}

Key words: Asparagus officinalis L., Heritability, Selective criteria, Parent-offspring regression method 


\section{INTRODUCTION}

Asparagus (Asparagus officinalis L.) is a perennial crop with high production costs. Profits can be improved by increasing the yield, which is a primary aim of breeding programs for this species. A variable genetic pool is necessary for the selection of more productive plants, and knowledge about yield and productivity heritabilities is extremely important for strategies designed to improve this crop.

Even after more than 100 years of research into ways of improving this crop, there is still little data on the heritability of A. officinalis. Legg et al. (1968) and López Anido et al. (1997) reported on broad-sense heritability and no information about narrow sense heritability. Correlation coefficients can help determine the secondary characters that would be useful as indicators of the more important ones under consideration (Johnson et al., 1955).

We estimated the narrow sense heritability and assessed the phenotypic correlation between vegetative and productive characters in white asparagus populations.

\section{MATERIAL AND METHODS}

Nine hundred plants from three white asparagus populations (Ohlsen-Enke, Vilmorin and Clause), of the cultivar Argenteüil, were studied for three years (1992-1994). At the end of the third harvest period, 32 pistillate and 64 staminate plants were selected based on their yield performance, and then left to open pollinate to obtain a population of 32 maternal half-sib families. Since asparagus is a perennial species, the population remained in the experimental field for several subsequent years. Selected plants were cloned by crown division, yielding four repetitions.

In December 1996, one-year-old crowns of the 32 families were planted in a randomized, complete block design with four replications in Zavalla, Argentina $\left(33^{\circ} 01^{\prime} \mathrm{SL}\right.$ and $60^{\circ} 53^{\prime}$ WL). Each repetition included eight plants per family. A cloned part of each family mother plant and two parental staminate plants chosen at random were also included at the beginning of each repetition. To eliminate the influence of environment and plant age on the estimate of heritability, a sample (600 plants) of the original populations (Ohlsen-Enke, Vilmorin and Clause) was planted in the same experimental field at the same time. The planting grid consisted of $2 \mathrm{~m}$ between rows and $0.45 \mathrm{~m}$ between crowns within a row.

During the spring of 1997, the following variables were evaluated in parental plants and their offspring (both planted in 1996): days to harvest, number of days from the cutting of the green top to the emergence of the first spear, number of spears and average diameter of spears. In April 1998 (final growth period), the green tops were cut and the following vegetative characters evaluated: number of stalks and plant height and weight when cut at ground level.

The variables that did not fit the assumption of a normal distribution were transformed as $x^{\prime}=\sqrt{ } \mathrm{x}+\sqrt{ }(\mathrm{x}+1)$.

The selection differential (S) was calculated as the deviation of the phenotypic means of selected parental (cloned) plants relative to the corresponding means of the original population. The response to selection $(\mathrm{R})$ was estimated as the difference between the phenotypic means of the progeny and the mean of the original population (Falconer, 1991). In both cases, standardization was achieved using the expressions: $\mathrm{S}_{\mathrm{st}}=\mathrm{S} / \sigma_{\mathrm{pgo}}$ and $\mathrm{R}_{\mathrm{st}}=\mathrm{R} / \sigma_{\mathrm{pgo}}$, where $\mathrm{S}_{\mathrm{st}}=$ standardized selection differential, $\sigma_{\mathrm{pgo}}=$ phenotypic deviation in the parental population and $\mathrm{R}_{\mathrm{st}}=$ standardized 
selection response. The heritability for different characters was estimated as realized heritability, $\mathrm{h}_{\mathrm{st}}^{2}=\mathrm{R}_{\mathrm{st}} / \mathrm{S}_{\mathrm{st}}$, and by the parent-offspring regression method, using the mean phenotypic values of the offspring and those from the pistillate progenitor, where $h^{2}=2 b_{o p}$. The phenotypic correlation coefficients between variables were calculated as described by Falconer (1991).

\section{RESULTS AND DISCUSSION}

There were no significant differences in the mean values between the traits evaluated in the base population planted in 1992 and in 1996.

\section{Realized heritability}

The mean values for the parental population, selected fraction, offspring, selection differentials and selection response were calculated (Table 1). The values for realized heritability ranged between 0.18 and 0.68 , except for days to emergence, which had a value of zero (Table 2). The

Table 1. Mean values for the variables in the parental population (PAR), selected fraction (SEL) and offspring (OFF) for general population (G.P.), staminate plants (S.P.) and pistillate plants (P.P.). The differential of selection applied (S) and the response (R) obtained are also shown.

\begin{tabular}{llrcccccc}
\hline & & $\mathrm{N}$ & $\begin{array}{c}\text { Days to } \\
\text { emergence }\end{array}$ & $\begin{array}{c}\text { No. of } \\
\text { spears }\end{array}$ & $\begin{array}{c}\text { Spear diameter } \\
(\mathrm{mm})\end{array}$ & $\begin{array}{c}\text { Plant height } \\
(\mathrm{cm})\end{array}$ & $\begin{array}{c}\text { No. of } \\
\text { stalks }\end{array}$ & $\begin{array}{c}\text { Plant weight } \\
(\mathrm{g})\end{array}$ \\
\hline PAR & G.P. & 600 & $144.5 \pm 10.5$ & $5 \pm 2.08$ & $11.3 \pm 3.2$ & $120.9 \pm 30.0$ & $10 \pm 5.8$ & $192.0 \pm 126.7$ \\
& S.P. & 300 & $144.2 \pm 9.8$ & $5 \pm 2.14$ & $11.0 \pm 2.9$ & $116.1 \pm 29.1$ & $10 \pm 6.0$ & $179.0 \pm 123.1$ \\
& P.P. & 300 & $144.8 \pm 11.3$ & $6 \pm 2.02$ & $11.7 \pm 3.4$ & $127.9 \pm 28.6$ & $10 \pm 5.7$ & $211.2 \pm 128.8$ \\
SEL & G.P. & 96 & $140.3 \pm 8.9$ & $7 \pm 1.96$ & $12.5 \pm 2.5$ & $126.1 \pm 23.8$ & $16 \pm 7.2$ & $266.7 \pm 147.1$ \\
& S.P. & 64 & $139.5 \pm 8.4$ & $7 \pm 2.03$ & $12.2 \pm 2.3$ & $122.7 \pm 22.6$ & $16 \pm 7.2$ & $260.6 \pm 155.2$ \\
& P.P. & 32 & $141.8 \pm 9.8$ & $7 \pm 1.85$ & $13.0 \pm 2.7$ & $132.8 \pm 25.1$ & $15 \pm 7.2$ & $279.1 \pm 130.9$ \\
OFF & G.P. & 1234 & $147.9 \pm 9.5$ & $6 \pm 1.89$ & $11.7 \pm 1.8$ & $121.9 \pm 31.4$ & $13 \pm 6.6$ & $243.9 \pm 185.2$ \\
& S.P. & 611 & $147.0 \pm 9.3$ & $6 \pm 1.89$ & $11.7 \pm 1.7$ & $118.5 \pm 28.4$ & $13 \pm 7.0$ & $245.4 \pm 180.8$ \\
& P.P. & 623 & $147.8 \pm 9.2$ & $6 \pm 1.91$ & $12.1 \pm 1.8$ & $129.3 \pm 30.3$ & $11 \pm 6.0$ & $244.7 \pm 180.9$ \\
\hline S & G.P. & & 0 & $1.2(0.6) *$ & $1.2(0.4)$ & $5.2(0.2)$ & $5.6(1.0)$ & $74.7(0.6)$ \\
& S.P. & & 0 & $1.3(0.6)$ & $1.2(0.4)$ & $6.6(0.2)$ & $5.8(1.0)$ & $81.5(0.7)$ \\
& P.P. & & 0 & $1.2(0.6)$ & $1.3(0.4)$ & $4.9(0.2)$ & $4.7(0.8)$ & $67.9(0.5)$ \\
R & G.P. & & 0 & $0.3(0.1)$ & $0.4(0.1)$ & $1.0(0.0)$ & $1.6(0.3)$ & $51.9(0.4)$ \\
& S.P. & & 0 & $0.4(0.2)$ & $0.7(0.2)$ & $2.3(0.1)$ & $2.6(0.4)$ & $66.4(0.5)$ \\
& P.P. & & 0 & $0.3(0.2)$ & $0.4(0.1)$ & $1.4(0.1)$ & $1.2(0.2)$ & $31.5(0.3)$ \\
\hline
\end{tabular}

* Values in parentheses represent the standardized differential of selection $\left(\mathrm{S}_{\mathrm{st}}\right)$ and the response to selection $\left(\mathrm{R}_{\mathrm{st}}\right)$.

Table 2. Values of heritability calculated as realized heritability $\left(\mathrm{h}^{2}{ }_{\mathrm{s}}\right)$ and by the parent-offspring regression method $\left(h^{2} b_{o p}\right)$ for staminate plants (S.P.), pistillate plants (P.P.) and the general population (G.P.).

\begin{tabular}{lllll}
\hline Variables & $\begin{array}{l}\text { S.P. } \\
\mathrm{h}_{\text {st }}^{2}\end{array}$ & $\begin{array}{l}\mathrm{P} . \mathrm{P} . \\
\mathrm{h}_{\mathrm{st}}^{2}\end{array}$ & $\begin{array}{l}\mathrm{G} . \mathrm{P} . \\
\mathrm{h}_{\text {st }}^{2}\end{array}$ & $\begin{array}{c}\mathrm{G} . P . \\
\mathrm{h}^{2} \mathrm{~b}_{\text {op }}\end{array}$ \\
\hline Days to emergence & 0 & 0 & 0 & 0.14 \\
No. of spears & 0.34 & 0.31 & 0.34 & 0 \\
Spear diameter & 0.60 & 0.42 & 0.58 & 0.18 \\
No. of stalks & 0.44 & 0.25 & 0.28 & 0.15 \\
Plant height & 0.35 & 0.45 & 0.18 & 0.22 \\
Plant weight & 0.68 & 0.66 & 0.59 & 0.34 \\
\hline
\end{tabular}

Genetics and Molecular Research 1 (1): 90-95 (2002) www.funpecrp.com.br 
general lack of genetic variability in this character reflected the strong indirect selection applied to the original stock to improve precocity because of the negative correlation between days to emergence and yield (Ellison, 1986).

For most of the variables, there were no large differences in heritability between the sexes, although means of 0.44 and 0.25 stalks were obtained for staminate and pistillate plants, respectively. For this character, intensive selection was applied to males, resulting in an $\mathrm{S}_{\mathrm{st}}$ of 0.98 and 0.83 for staminate and pistillate plants, respectively (Table 1). For spear diameter, the heritability was 0.60 for staminate plants and 0.42 for pistillate ones, with no differences in the intensity of selection between the sexes $\left(\mathrm{S}_{\mathrm{st}}=0.40\right.$ in both sexes). However, the response to selection $\left(\mathrm{R}_{\mathrm{st}}\right)$ was greater in staminate plants, with a larger influence of the additive component of the genetic variance for this character in males.

For the whole population (pistillate and staminate plants combined), greater values of heritability were obtained for spear diameter (0.58) and plant weight (0.59). Currence (1947) evaluated the offspring of selected plants of the 'Mary Washington' variety (green asparagus) and observed that spear diameter in the offspring was related to spear diameter in the parental population, demonstrating that this character could be determined by the parents' phenotype, thus inferring high heritability.

The number and diameter of spears produced per each plant are the principal components of yield in this species. The number of spears produced is highest during the second year so that an increase in the heritability for this variable is expected during the second year of production. In contrast spear diameter does not vary between the first and successive years (Cointry et al., 1996), so it is advisable to select for spear diameter during the first year and for spear number during the second.

\section{Heritability by regression}

The heritability values determined by the regression method were generally $50 \%$ lower (Table 2), with the exception of days to emergence $\left(\mathrm{h}^{2}=0.14\right)$. For this method, only female progenitors were considered. This procedure may have introduced a bias into the results since heritability (calculated as realized heritability) showed higher values for staminate plants, with the only exception being plant height, although the differences between the values of heritability obtained for the general population were less by both methods. As stated by Falconer (1991): "selection causes the variance between parents to be reduced and consequently the covariance of sibs to be reduced. As a result, the heritability estimated from intraclass correlation is biased and can be as much as $50 \%$ below its true value. If the selection of parents is based on the character whose heritability is being estimated, it does not affect the regression of offspring on parents, but it reduces the precision because it reduces the variance of the parents."

Legg et al. (1968) reported heritability values of $0.18,0.24,0.29$ and 0.33 for spear diameter, days to emergence, number of stalks and plant weight, and López Anido et al. (1997) obtained similar values $(0.15,0.27,0.12$ and 0.16 , respectively). These values were lower than those obtained here, especially for realized heritability. Since heritability is not a property of the character alone, but also reflects populational and environmental circumstances, the heritability for a given character must be understood to refer to a particular population under particular conditions (Falconer and Mackay, 1997). 


\section{Phenotypic correlation}

Since a large number of characters must be considered in a selection program, it is necessary to know their heritability and the relationships between them in order to choose the selection model to be used. Phenotypic correlation (Table 3 ) revealed a relatively high association

Table 3. Phenotypic correlations between variables evaluated in asparagus offspring.

\begin{tabular}{lccccc}
\hline & Plant weight & No. of spears & Spear diameter & Days to emergence & Plant height \\
\cline { 2 - 6 } No. of stalks & $0.67^{* *}$ & $0.62^{* *}$ & $0.13^{*}$ & $-0.50^{* *}$ & $0.30^{* *}$ \\
Plant weight & & $0.44^{* *}$ & $0.41^{* *}$ & $-0.39^{* *}$ & $0.61^{* *}$ \\
No. of spears & & & $-0.03 \mathrm{~ns}$ & $-0.36^{* *}$ & $0.21^{* *}$ \\
Stalk diameter & & & & $-0.26^{* *}$ & $0.46^{* *}$ \\
Days to emergence & & & & & $-0.27^{* *}$ \\
\hline
\end{tabular}

$* * \mathrm{P}<0.01 ; * \mathrm{P}<0.05 ;$ ns $=$ not significant.

between the number of stalks and plant weight $(\mathrm{r}=0.67, \mathrm{P}<0.01)$, and between plant weight and height $(\mathrm{r}=0.61, \mathrm{P}<0.01)$, indicating that the weight of the green top is fundamentally related to these characters. There was also a significant positive correlation between the number of stalks and the number of spears, probably because both originate from the same growth buds in the crown. Similar results have been reported by Tiedjens (1924), Ellison and Scheer (1959) and Ellison (1986), who also demonstrated a negative correlation between the number and diameter of spears. In our study, both of these variables were also negatively related, though the correlation was not significant. Haber (1932) similarly found no significant correlation between these variables, whereas Pandita and Bhan (1990) found a significant value of -0.20 . These values were not considered useful for improvement programs. Finally, there was a significant, negative correlation between days to emergence and all the other characters, probably because of the strong selection applied.

\section{CONCLUSIONS}

Based on the high heritability shown by the different characters, especially the yield components (spear number and diameter), we conclude that the determinant genetic effects of the phenotypic expression of these characters are fundamentally of the additive type. For this reason, a high response should be achievable after several selection cycles. In addition, the high association between number of stalks (an easily measured vegetative variable) and number of spears (principal yield component) should allow for the selection of productive plants based on vegetative characters.

\section{REFERENCES}

Cointry, E.L., López Anido, F.S., Gatti, I., García, S.M. and Firpo, I.T. (1996). Comparative study of morphological and productive characters in blanched asparagus populations. Asp. Res. News. 13: 30-34.

Currence, T.M. (1947). Progeny tests of asparagus plants. J. Agric. Res. 74: 65-76.

Ellison, J.H. (1986). Asparagus breeding. In: Breeding Vegetable Crops (Bassett, M.J., ed.). Avi Publisher Co., Westport, CT, USA, pp. 521-569.

Ellison, J.H. and Scheer, D.F. (1959). Yield related to brush vigor in asparagus. Proc. Am. Soc. Hortic. Sci. 73: 339-344. 
Falconer, D.S. (1991). Introduction to Quantitative Genetics. John Wiley and Sons, New York, NY, USA.

Falconer, D.S. and Mackay, T.F.C. (1997). Introduction to Quantitative Genetics. Longman Group Ltd., Edinburgh Gate, Harlow Essex, England.

Haber, E.S. (1932). Effect of size of crown and length of cutting season on yields of asparagus. J. Agric. Res. 45: 101-110.

Johnson, H.W., Robinson, H.F. and Comstock, R.E. (1955). Genotypic and phenotypic correlations in soybeans and their implications in selection. Agron. J. 47: 477-483.

Legg, P.D., Souther, R. and Takatori, F.H. (1968). Estimates of heritability in Asparagus officinalis from replicated clonal material. Proc. Am. Soc. Hortic. Sci. 92: 410-417.

López Anido, F.S., Cointry, E.L., Picardi, L. and Camadro, E. (1997). Genetic variability of productive and vegetative characters in Asparagus officinalis L. - Estimates of heritability and genetic correlations. Braz. J. Genet. 20: 275-281.

Pandita, P.N. and Bhan, M.K. (1990). Variability and correlation in asparagus (Asparagus officinalis). Indian J. For. 60: 487-488.

Tiedjens, V.A. (1924). Some physiological aspects of Asparagus officinalis. Proc. Am. Soc. Hortic. Sci. 21: 129-140. 